\title{
ORIGINAL ARTICLE \\ A System for Three-Dimensional Shape Measurement and its Application in Microtia Ear Reconstruction
}

\author{
Tsuyoshi Kaneko \\ Department of Plastic and Reconstructive Surgery, School of Medicine, Keio University, Tokyo, Japan
}

(Received for publication on January 21, 1993)

\begin{abstract}
Microtia is one form of ear anomalies representing the defect of a partial or total loss of external ear. This paper describes new method of total auricular reconstruction which combines the use of tissue expander and the non-contact, 3-dimensional (3-D) shape measurement system. The anterolateral and posterior surface of the both sides of the ear of the patients were measured with the 3-D shape measurement system. The data from normal side was mirror-imaged electronically and transferred to the computer-controlled milling machine to create the life-sized, mirror-image wax model. These models were sterialized and used as a template or an aid during assembling procedure of the autologous cartilage framework in order to reproduce the 3-D configuration of the wax model. Seven cases were treated with this method and 5 cases $(\mathbf{7 2} \%)$ were graded as excellent (superior to that result obtainable from conventional methodology), one each (14\%) was good (better result) and fair (the same level). There are no poor evaluations. In two cases, the exposure of the expander, one of the major complications, developed. Although additional surgery was needed, excellent and fair result was obtained in these cases. It was concluded that the method presented here was evaluated as an overall good method and its application should be further extended. (Keio I Med 42 (1): 22-40, March 1993)
\end{abstract}

Key words: microtia, auricular reconstruction, three-dimensional shape measurement system, computer simulation surgery, tissue expansion

Introduction

Microtia is one form of the ear anomalies affecting the ear and represents the defect of a partial or total loss of external ear. The degree of the defect varies in individuals and some patients accompany auricular atresia and/or abnormality of the middle ear. About the half of the microtia patients have some characteristics of the first and second branchial syndrome such as macrostomia, facial nerve palsy and unilateral facial hypoplasia (mainly mandible).

Although this is a relatively rare anomaly with an incidence of one to $6,000^{1}$ or $12,500^{2}$, the reconstruction of the auricle of these patients has been a challenging problem for plastic surgeons because these patients not only suffer from the esthetic problem but also functional problems such as inability to wear eye-glasses, masks and hearing-aids. Auricular reconstruction for microtia patients still remains one of the most difficult surgeries in the field of plastic surgery. A lot of factors including for example the size, shape, axis, texture, degree of undulation and shape of the posterior fold must be considered to achieve a natural looking auricle.

After Converse ${ }^{3}$ and Tanzer ${ }^{4}$ established the use of the autologous rib cartilage platform, numerous attempts and modifications have been added. One of the most important refinements is the use of the tissue expanders. Tanino ${ }^{5,6}$ and $\mathrm{Hata}^{7}$ have successfully introduced the tissue expanders, which have been well established in the other fields of plastic surgery, into the delicate surgery associated with auricular reconstruction. First the tissue expander is inserted under the temporal skin and inflated with saline to develop abundant skin. This enables the surgeon to insert more 3-D cartilage framework. However, the problem exists as to how we can manufacture "real" or realistic 3-D cartilage framework. If the contralateral external ear of the patient is nearly normal, the author proposes that the new ear should be reconstructed as much as possible the mirror-image of the contralateral auricle. This can be facilitated if a mirror image life-size

金子判

Rcprint requests to: Tsuyoshi Kaneko MD, Department of Plastic and Reconstructive Surgery, School of Medicine, Keio University, 35 Shinanomachi, Shinjuku, Tokyo, 160, Japan. 
model of the contralateral auricle is available at hand during surgery and can be used as an aid. However to date there has been no reliable method to make this kind of model.

A new non-contact 3-D shape measurement system using laser slit-lamp scanning ${ }^{8}$ has been originally developed in order to meet the growing demands for digital shape measurement in industrial design, fashion design and medical science. From basic experimental studies this system has proved to be especially useful for measurement of any part of human body. In this paper a new approach of the auricular reconstruction with the combined use of the non-contact 3-D shape measurement system and tissue expanders is described and evaluated and the possible utility of this system is discussed.

\section{Patients}

A total of 7 patients with congenital microtia (4 males and 3 females) underwent auricular reconstruction with this method between July 1991 and August 1992. Their age ranged from 7 years and 7 months old to 10 years and 2 months old. The mean was 9 years and 1 month.

The 5 male patients presented with microtia involving complete hypoplasia of the left side with atresia of external meatus although there were minimal variations. The other 2 female patients had microtia of the right side. One patient had complete hypoplasia type and another patient had conchal remnant type.

\section{Method}

\section{3-D Shape Measurement System}

The system used is the VOXELAN system which was developed, and is currently marketed by NKK cooperation $^{8}$. This system is composed of the optical head consisting of the laser beam generator, two rotating mirrors, charge-coupled device (CCD) camera and an image encoder, a personal computer and a video monitor (Fig. 1 and 2).

The principle of the system is shown in Fig. 3. Light from the laser slit lamp is scanned on the subject by two oscillating mirrors. The object and the light patterns on it are recorded by the CCD camera in front of the object and the field is divided into $256 \times 240$ pixels. The image encoder processes the image from the CCD camera in a real time manner to synthesize the encoded image of projection angle of the slit lamp when each pixel becomes brightest by the slit light. This image is then transformed to obtain the height image of the object by each pixel through the triangulation method. In order to prevent any "noise" from the background light or the coloration

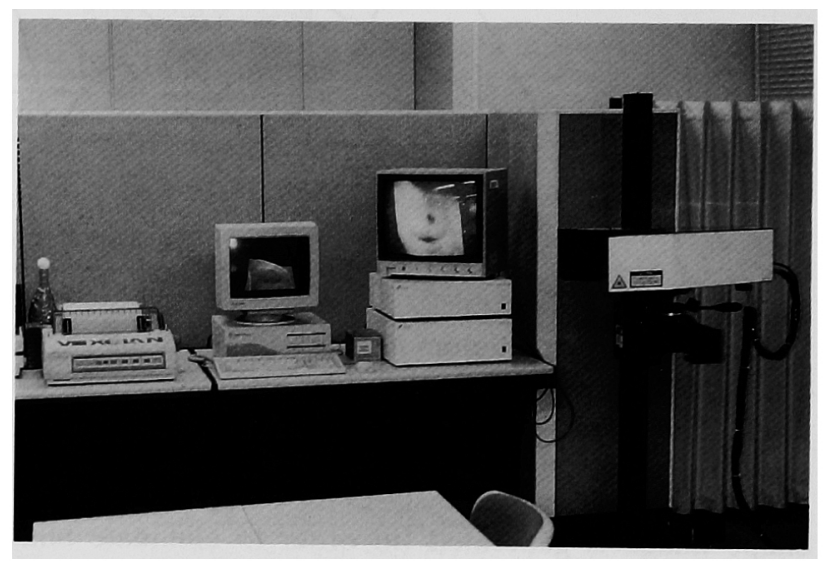

Fig 2 Components of the 3-D shape measuring system (from the left, plotter, PC-9801RA with hard disc drive, video monitor, image encoder and laser controller and optical head).

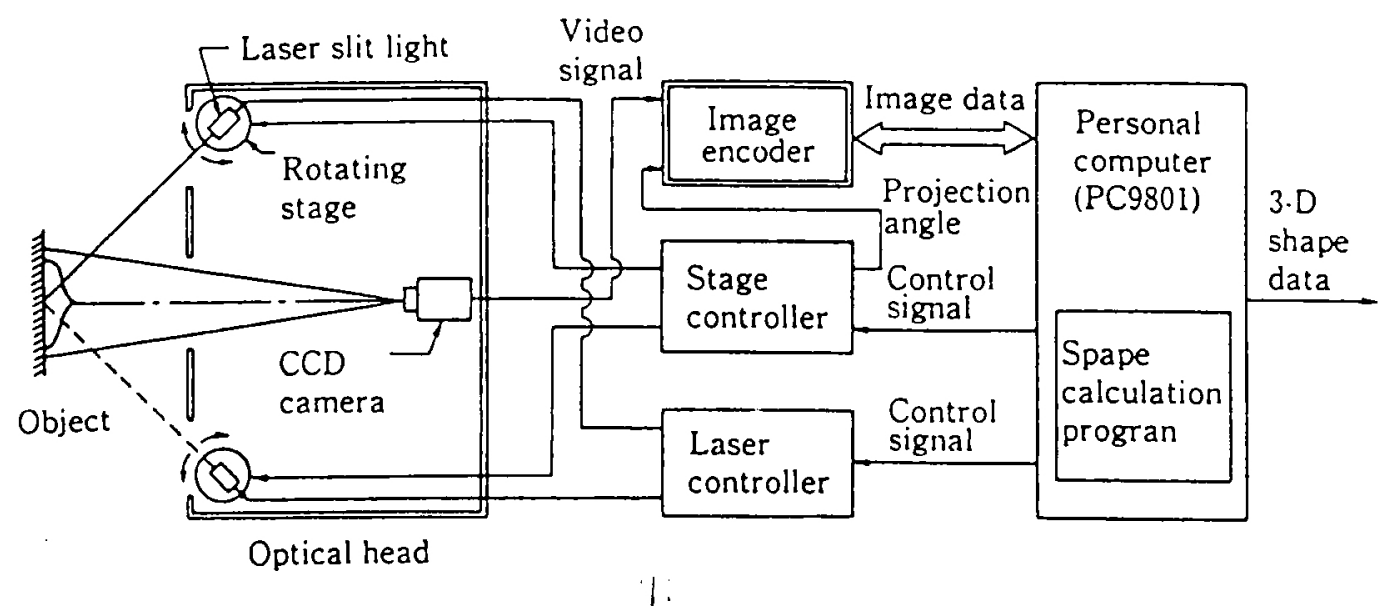

Fig 1 Schematic diagram of 3-D shape measurement system (reprinted from Ucsugi and Inomata ${ }^{8}$ ). 


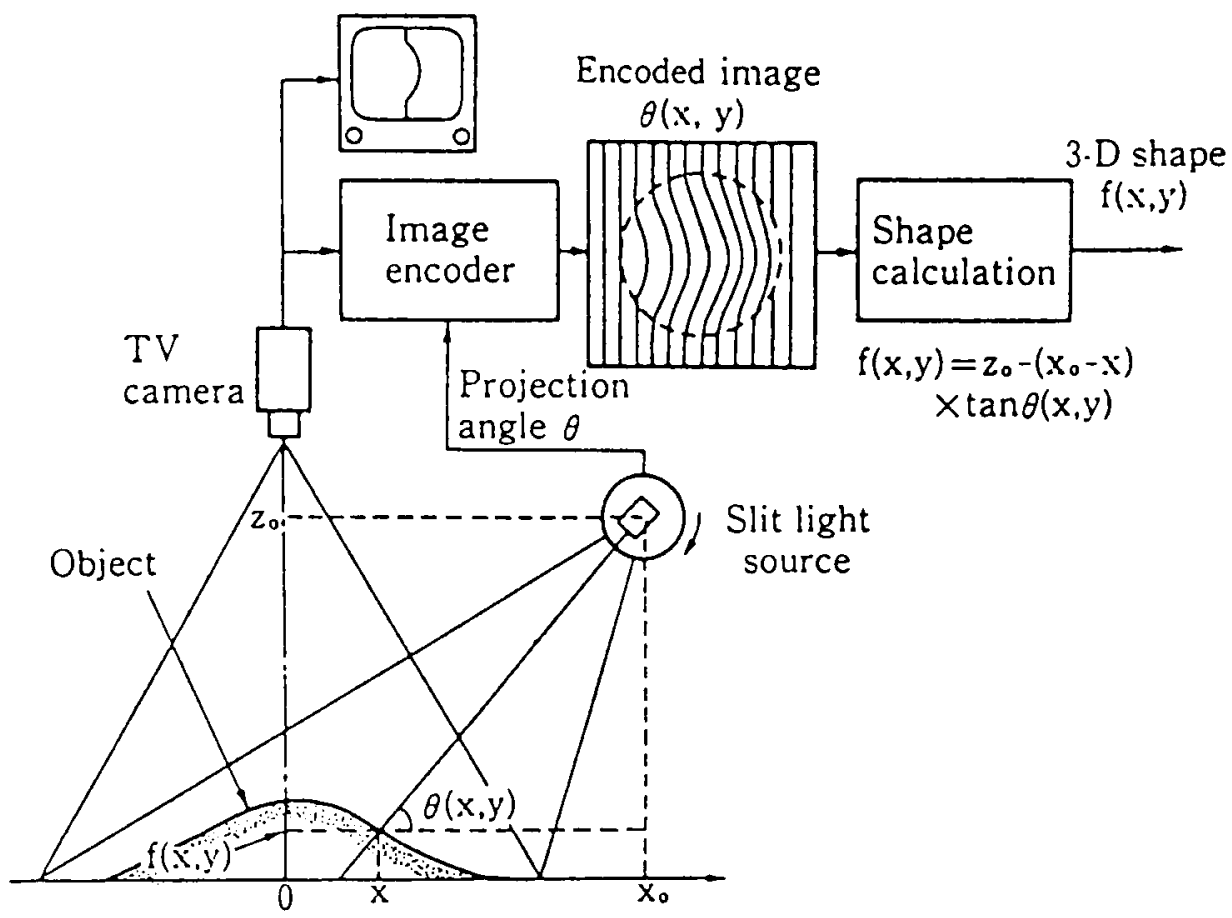

Fig 3 Basic principles of 3-D shape measurement (reprinted from Uesugi and Inomata ${ }^{8}$ ).

of the object, the minimum intensity image is subtracted from the maximum intensity image, and effective area is defined as a mask image. Then image of the shape is generated only in the effective area by this masking procedure. A composite image of the bilaterally-generated shape image is generated (in order to eliminate blind spots) and then perspective distortion as a result of the optical lens system is finally corrected. The 3-D shape image is shown in grayscale or wire frame form. The block diagram of the system is shown in fig. 4 .

The data can be stored in diskettes so that later manipulation such as calculation of surface area and volume can be performed.

The specifications of the system are shown in Table 1.

\section{Measurement of the ear}

The anterolateral and posterior surface of the both sides of the auricle were measured. The external ear is a very complicated object and meticulous positioning of the optical head and the patients' head was required to minimize the blind spots which were likely to exist conchal wall, just posterior to the tragus and the hooding of helix. Repositioning was aided by a video monitor which showed a live image of the ear, and the optical head was fixed so that the above mentioned area could be seen as much as possible. Although it took only 10 seconds (4 seconds for each scan and interscan interval of 2 seconds') to complete measurement, we found some difficulty in stabilizing the child's head during measurement and a chair with a head rest was used for later cases. However, even when there were motion artifacts the measurement could be easily repeated and reliable data could be obtained. It was more difficult to measure posterior surface of the ear because the narrow angle of the auricle and temporal skin did not permit the slit laser beam reach deep into the posterior sulcus. In this situation rotating the optical head upright and transforming the laser scanning to the vertical mode minimized the blind spots effectively (Fig. 5).

\section{The mirror image, life-sized wax model}

The contralateral external ear, as measured above, was then mirror-imaged electronically and transferred to a computer-controlled milling machine (CAMM-3 from Roland. Fig. 6). Mirror image, life-size wax models of the anterolateral surface and posterior surface of the auricle were made for each patient and prepared for reconstructive procedure. The wireframe and the solid wax ear models generated from the 3-D slit-lamp measurement data are shown in Fig. 7-9.

\section{Operative procedure}

\section{Expanders}




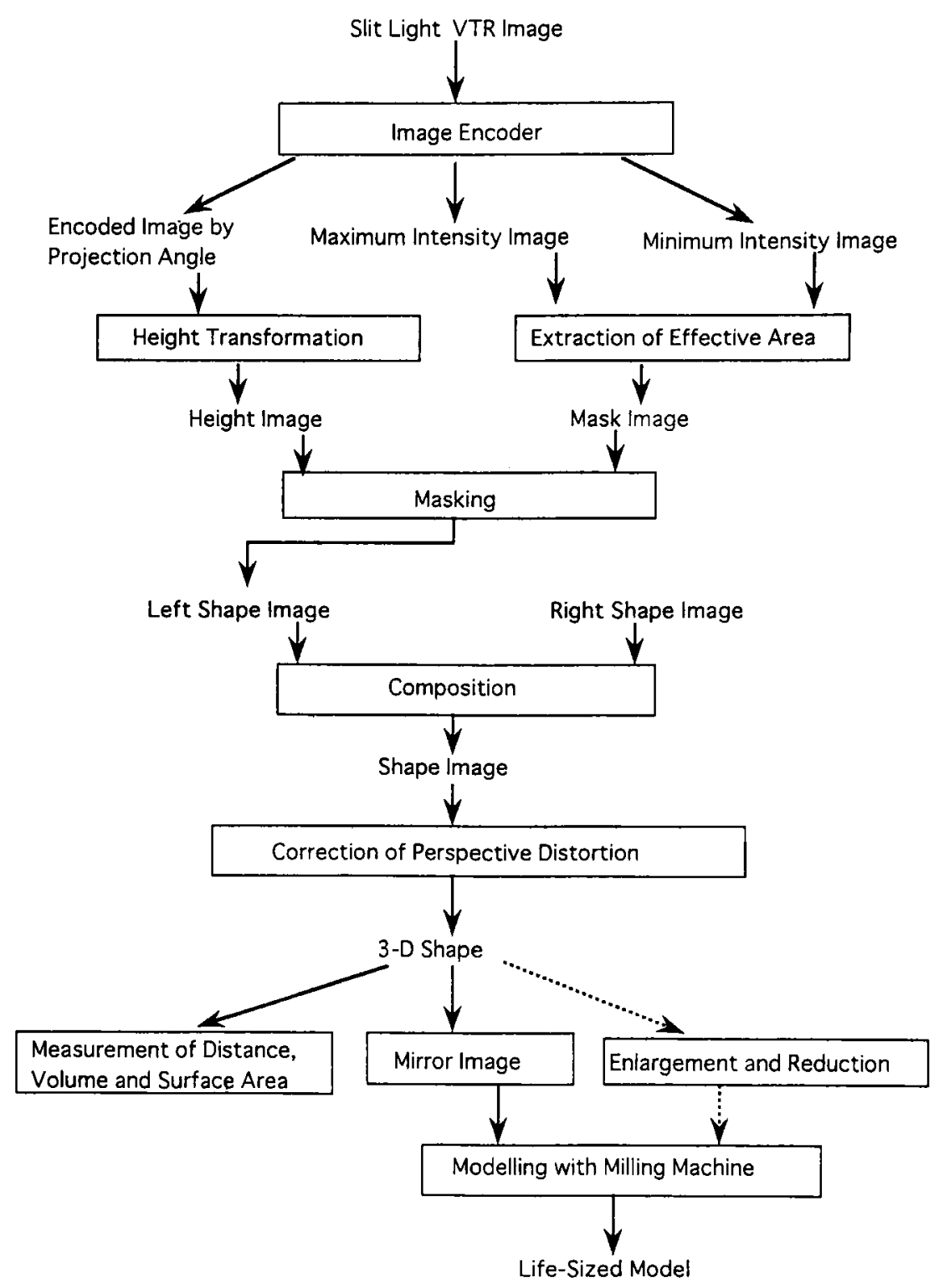

Fig 4 Blockdiagram of 3-D Shape measurement System (revised from Uesugi and Inomata ${ }^{8}$ ).

Four types of expanders were used in this study. KOKEN No. 1504 (fig. 10a) was used in case 1, 3 and 5. This is a rectangular based expander with a slightly curved shape, measuring $5.0 \mathrm{~cm}(\mathrm{~L}) \times 4.0 \mathrm{~cm}(\mathrm{~W})$ at the base, $4.0 \mathrm{~cm}$ in height and with a volume of $55 \mathrm{ml}$. KOKEN No. 1483 (fig. 10b) was used in case 4. This is round in shape with the diameter and height of $5.0 \mathrm{~cm}$ and a volume of $75 \mathrm{ml}$. PMT No. 3605-16 was used in case 2 . This product is of the same shape and volume as the KOKEN 1483, but is made of soft expandable silicone eliminating wrinkle formation. PMT No. 3610-18 was used in case 6 and 7 . This product is rectangular, $6 \mathrm{~cm}$ in length, $5 \mathrm{~cm}$ in width and $95 \mathrm{ml}$ in volume, and is made of a softer elastic silicone material than No. $3605-16$.

First stage (Fig. 11a-11d)

Under general anesthesia the temporal skin on the affected side was infiltrated with saline to which epinephrine had been added. The straight incision about $4-5 \mathrm{~cm}$ long was placed in the temporoposterior hair bearing area. Sub-cutaneous dissection was performed 
Table 1 Specification of the System

1) Three dimensional shape measurement system: VOXELAN system (NKK corporation)

Size of measurement field: $130 \mathrm{~mm} \times 122 \mathrm{~mm}$

Working distance: $210 \mathrm{~mm}$

Precision: $0.4 \%$ of the measurement field $(0.5 \mathrm{~mm})$

Laser scanning time: 10 scconds

Shape reconstruction time: 30 seconds

Laser light source: Diode laser $5 \mathrm{~mW}, 670 \mathrm{~nm}$

Personal computer: NEC PC9801DA or RA

2) Computer controlled milling machine: CAMM-3 (Roland)

Working field: $180 \mathrm{~mm} \times 150 \mathrm{~mm} \times 150 \mathrm{~mm}$

Resolution: $0.01 \mathrm{~mm} / \mathrm{step}$

Working speed: $1.2 \mathrm{~m} / \mathrm{min}$

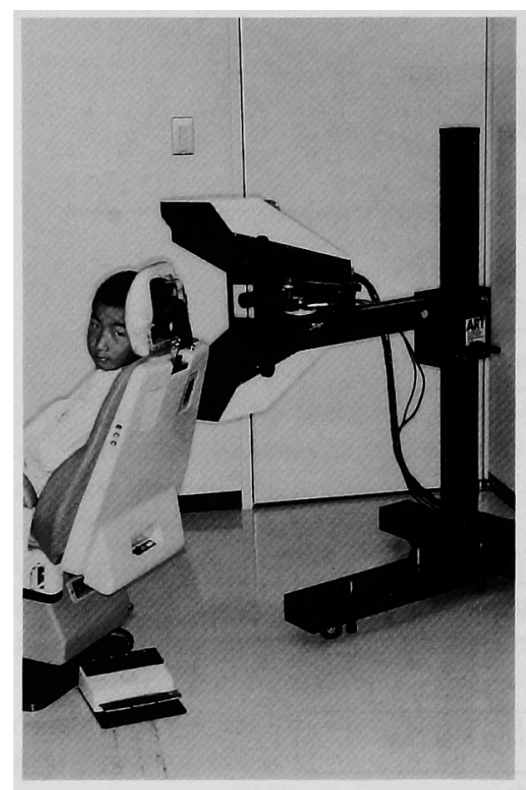

Fig 5 The optical head and a patient sitting on the dental chair. Notc the optical head is rotated 90 in order to measure the retroauricular area.

anteriorly from this incision to temporal skin just under and across the remnant on the subfollicular plane. The tunnel from the incision and temporal area was made as narrow as possible so that the expander would not migrate into the hair-bearing area. The pocket was formed to just as the same size of the expander beneath the hairless skin in order to avoid expanding and recruiting the hairy scalp. Hemostasis was completed and a tissue expander was inserted. Normal saline to about $10-15 \%$ of maximum capacity of the expander was injected from the port. The port was buried in the subcutaneous pocket in the mastoid area from the same incision. A suction drain was left and the incision was closed in two layers. The

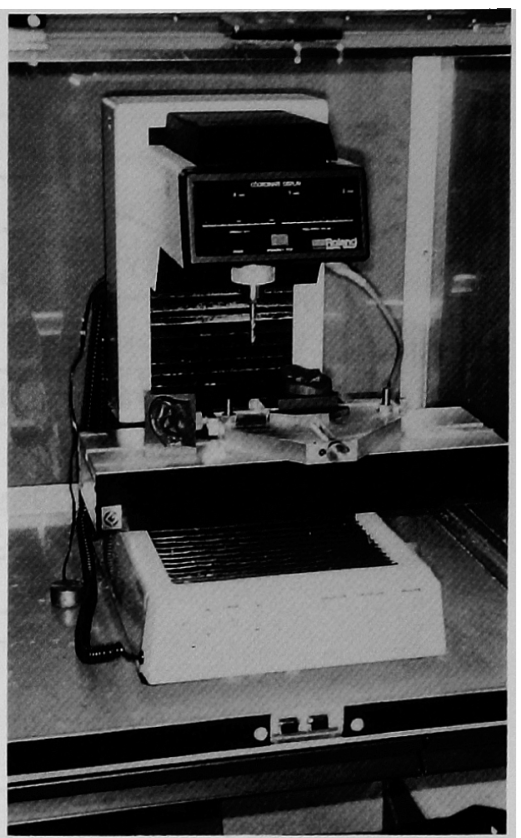

Fig 6 Computer-controlled milling machine (CAMM-3 from Roland)

color of the skin on top of the expander was observed carefully for a few days and the suction drain was removed, following which the patient was discharged.

After allowing about two weeks for firm healing, the first percutaneous injection of normal saline, usually $5-10 \%$ of the full expansion volume, began. Furthur injections were done once or twice a week and the volume each time was $6-7 \mathrm{ml}$ depending on the pain, skin color and tension. For most of the patients it took 2 months to arrive at the full-or over-expansion to allow reconstruction.

\section{Second stage (Fig. 11e-11i)}

Under general anesthesia the expander was extracted through the same incision. The thick capsule of the fibrous tissue at peripheral edge of the expander was excised and/or incised. The capsule beneath the thin, expanded temporal skin was left untouched for fear that this might jeopardize the vascularity of the expanded flap. The cartilage of the remnant is extracted very carefully in order not to make holes and damage small vessels.

A skin incision about $7 \mathrm{~cm}$ long is placed on the anterior chest and 3 rib cartilages (usually $7 \mathrm{th}, 8$ th and 9th) were harvested, and the perichondrium, muscles and skin were closed in layers. Then the cartilage framework was assembled and sculpted using fine surgical stainless steel wires and nylon sutures. The mirror image, life-sized wax model was sterilized and the cartilage was 

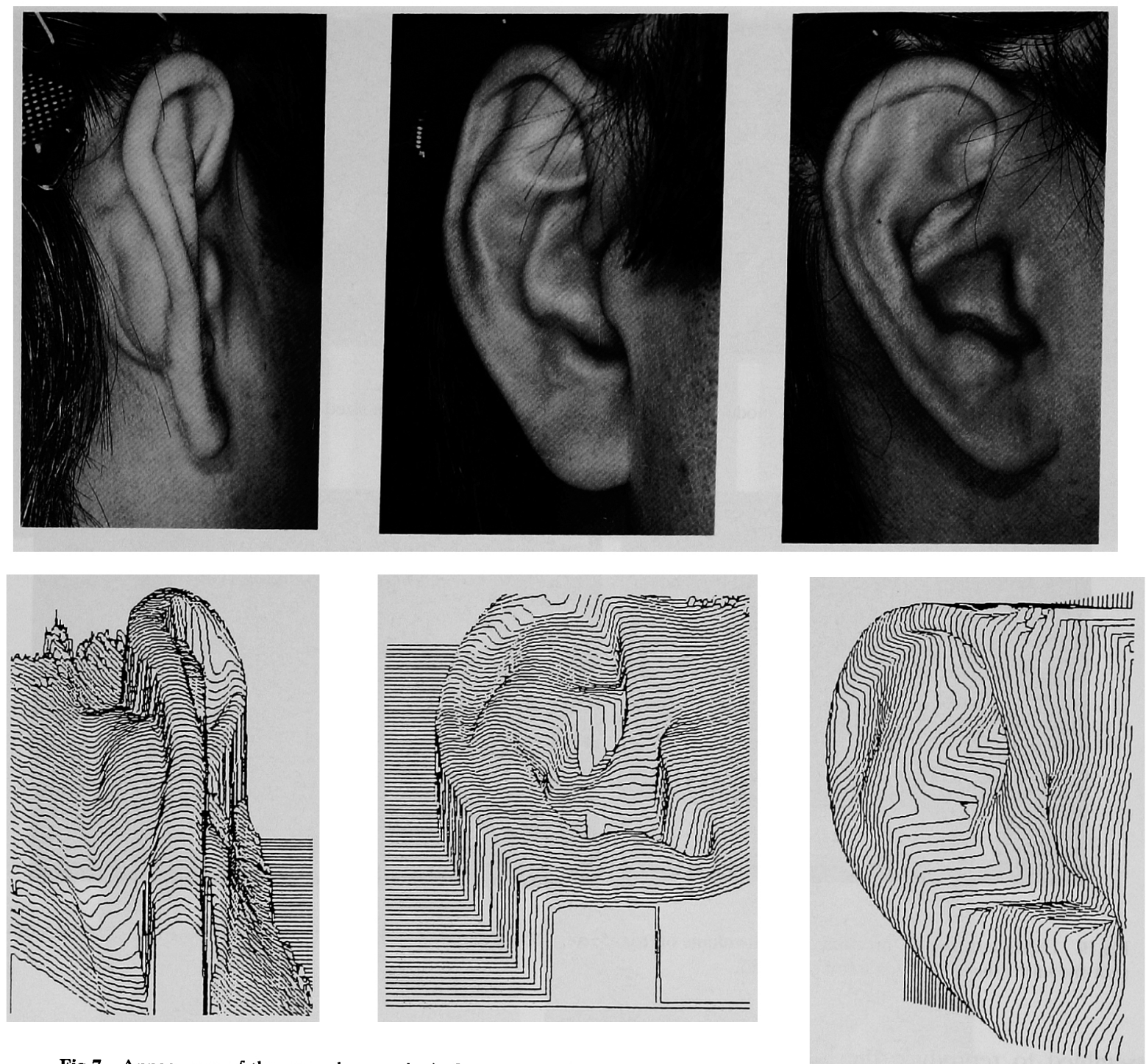

Fig 7 Appearance of the normal ear and wireframe expression of the 3-D data obtained from the Voxelan system.

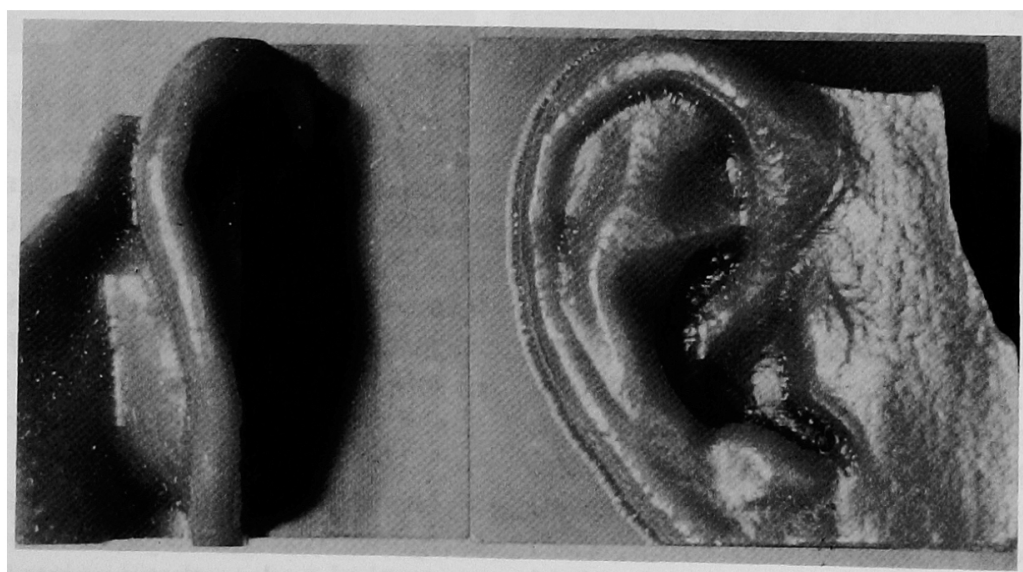

Fig 8 Life-sized wax model from the same data as seen in Fig. 7. Note the characteristics of the auricle are clearly demonstrated. 


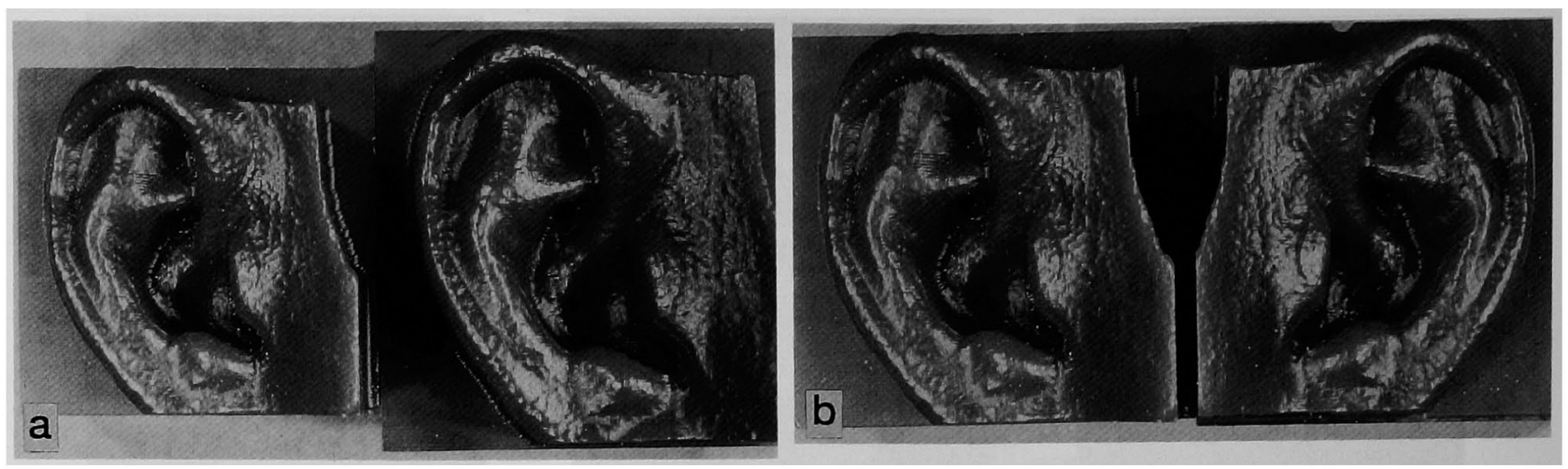

Fig 9 a. Life-sized wax model and an enlarged (1.2) wax model b. Life-sized mirror image models.

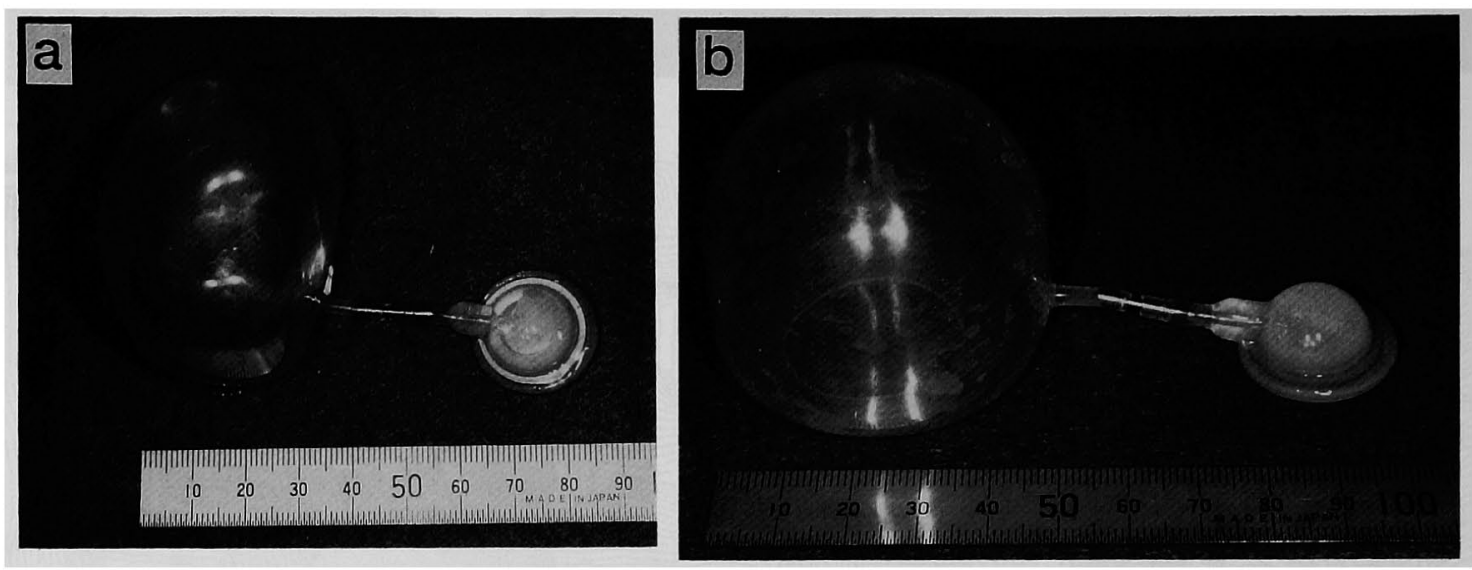

Fig 10 Expanders used in this study. A total volume of from $55 \mathrm{ml}$ to $95 \mathrm{ml}$ was used. a. Koken \#1504. b. Koken \#1483. PMT \#3605-06 (not shown) is the same size of Koken \#1483.

assembled to reproduce the 3-D configuration of the wax model. In most of the cases the 9th cartilage was used as the helix, while the symphysis of 7 th and 8 th rib cartilage was used to make main frame of the platform and antihelix. Additional pieces from 7th and 8th cartilage were used to make the wall of concha. Accurate reporduction of concha and antihelix was stressed in this series. Any harsh or sharp edge were cut to make smooth surface to avoid showing through the very thin skin coverage.

The platform was then inserted under the temporal skin. The platform should be positioned symmetric with the facial axis. The positioning of the platform was very critical and was helped with then use of mirror-image film pattern on which the oral angle, nasal ala and lateral canthus were marked. After insertion of a suction drain, the incision was closed in two layers.

Bolster sutures were placed to eliminate the dead space between the temporal skin and the platform and to define the contour of the skin on the platform. The skin color under the bolster suture was checked every day and the suction drain was kept in for one week. The bolster sutures were removed in 2 weeks.

Third stage and/or forth stage (Fig. 1lj-l)

Transposition of the lobules of the remnant was done as the third stage. In 2 cases the imbedded platform was elevated from the temporal lesion, and full thickness skin grafting and small triangular flap transfer was performed to make retroauricular sulcus. Efforts to simulate tragus were carried out in some cases.

\section{Results}

The reconstructed auricle was evaluated under 4 categories (excellent, good, fair and poor) from both anatomical and aesthetic points. The location, the inclination of the axis, size, the degree of erection, the 

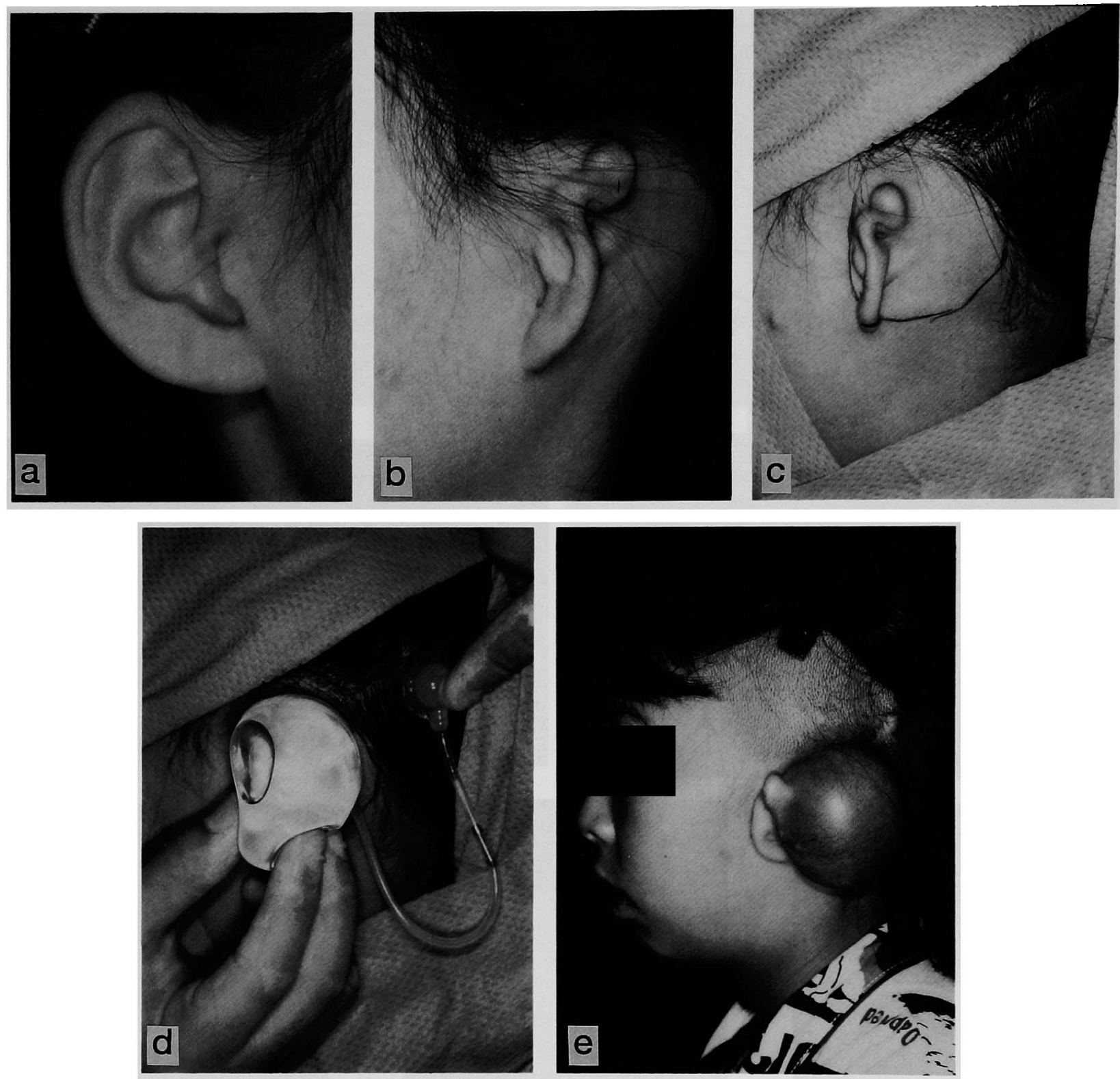

Fig 11 Case 1. a. Close-up view of the ear on the normal side. b. Close-up view of the affected side. Microtia of complete hypoplasia type. c. Intraoperative view: Incision line in the scalp and the area of undermining for expander is shown. $\mathrm{d}$. The expander used in this case is shown (KOKEN No. 1504, total capacity is $55 \mathrm{ml}$ ). e. Appcarance just before the second stage. The expander is over expanded to $73.5 \mathrm{ml}$.

shape of the helix and antihelix and presense of high conchal wall and tragus were also included in the evaluation. From the aesthetic point, a natural-looking auricle was evaluated highly. 'Excellent' was graded superior to that result obtained from conventional method, 'good' for better result than conventional methodology, 'fair' for the same level and 'poor' means worse than the result obtainable by conventional methodology. In this series 5 cases $(72 \%)$ are graded as excellent, one each $(14 \%)$ was good and fair. There were no poor evaluations.
In 5 patients (Case 1, 2, 3,6 and 7) in whom complication-free skin expansion was carried out, it was possible to reconstruct an erect, 3-D auricle. In 4 patients the skin was thin and pliable and its pinkish color resembled the contralateral natural auricle. These auricles were graded excellent. In one patient (Case 2) shrinkage of the expanded skin was severe compared to the rest of the cases, the retroauricular sulcus was lost and late elevation of the auricle with full thickness skin grafting was required. Although an erect, 3-D ear was obtained, some of the 

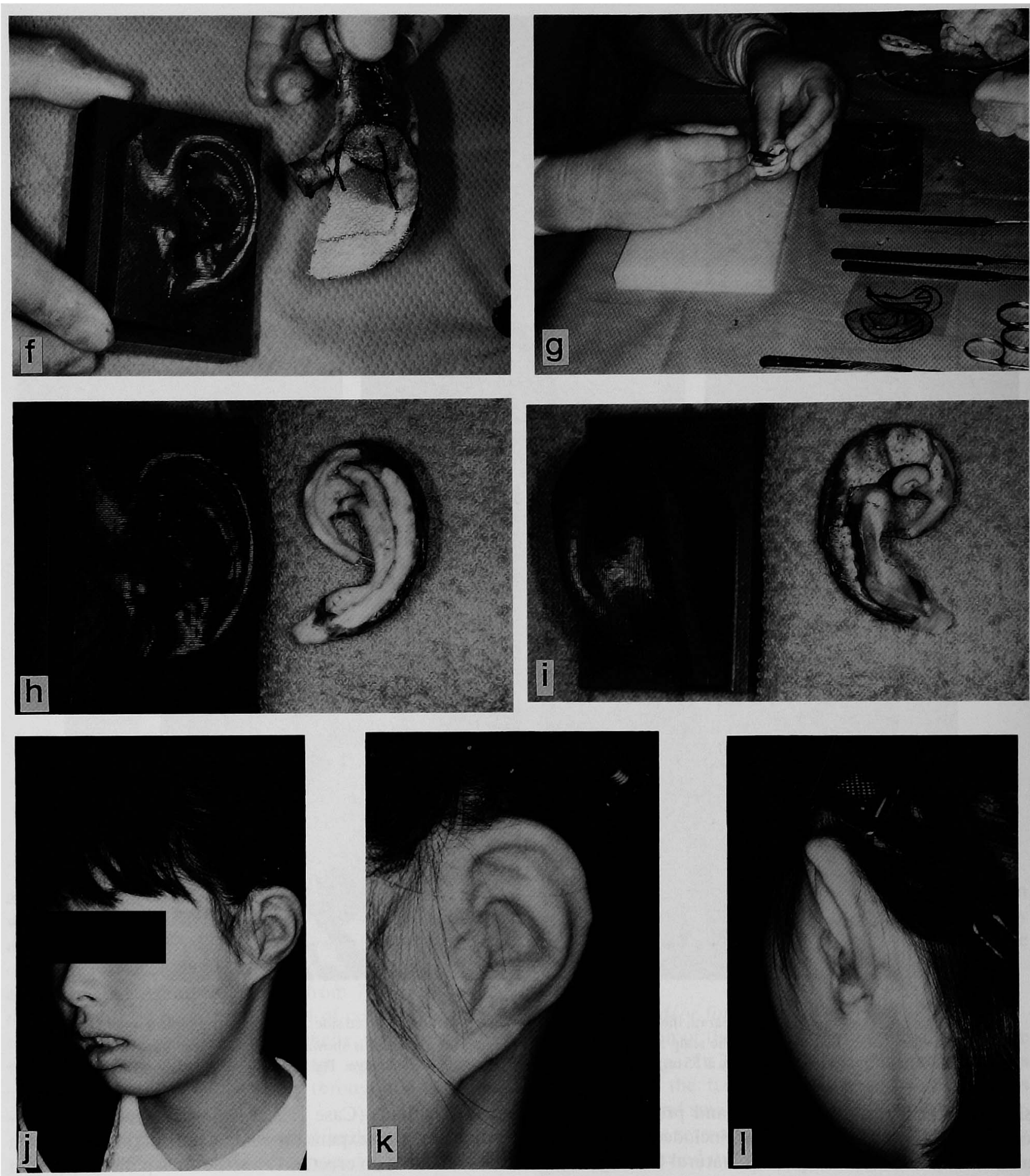

Fig 11 Case 1. f. The life-sized wax model and the 7th and 8th rib cartilage (below the reverse film pattern). The 9th cartilage is not shown. g. The autologous cartilage framework is carved and assembled with the life-sized mirror-image model as an aid. $h$. Three dimensional cartilage framework and the wax model: anterior view. i. Same as above, posterior view. Note the reconstruction of the conchal wall to make a erected auricle. j.-l. 1-year postoperative appearance. Naturally erect auricle with deep convolution is shown. 

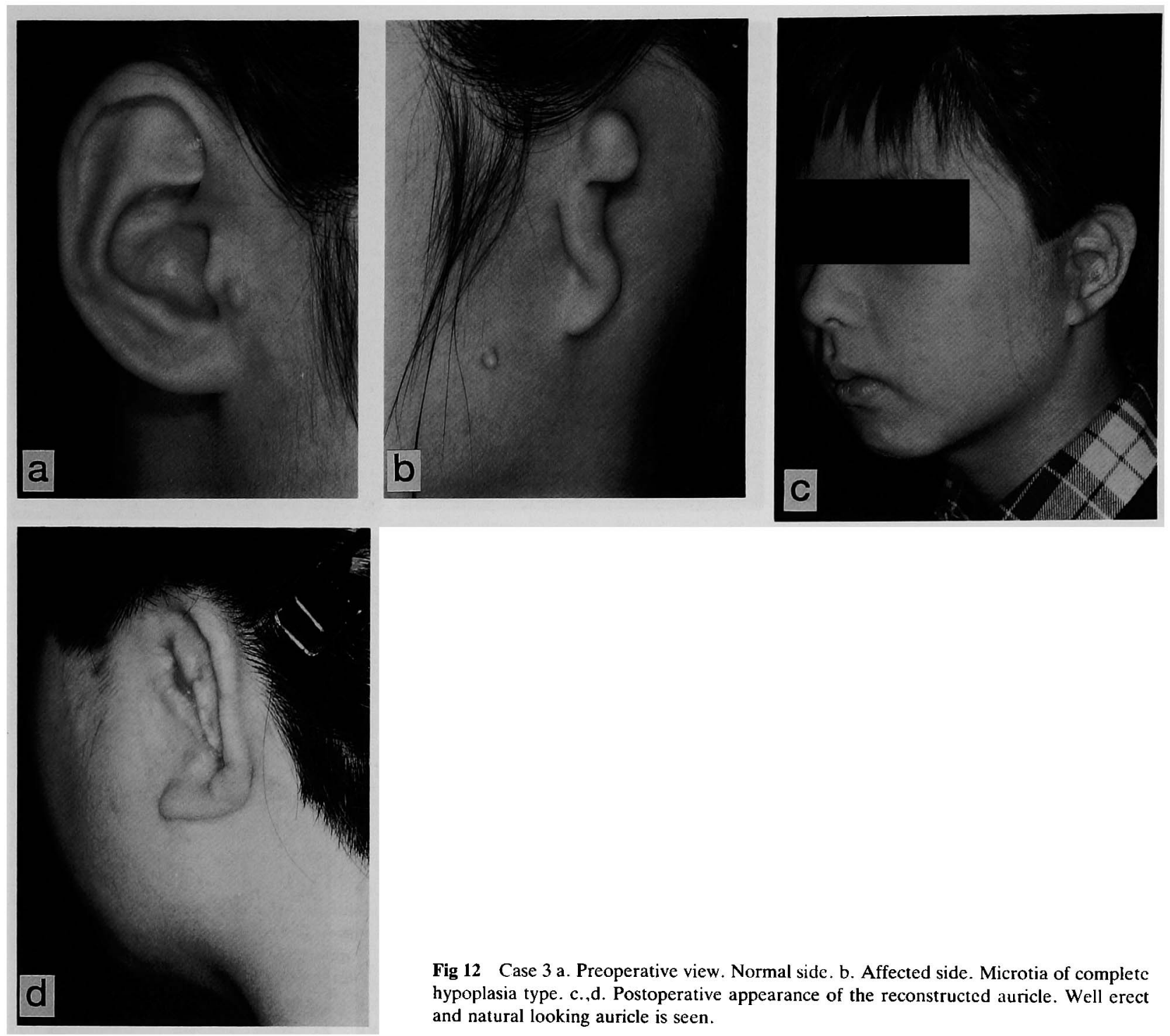

Fig 12 Case 3 a. Preoperative view. Normal side. b. Affected side. Microtia of complete hypoplasia type. c.,d. Postoperative appearance of the reconstructed auricle. Well erect and natural looking auricle is seen.

original contuor was lost and it was graded fair.

In 2 patients (Case 4 and 5) exposure of the expanders developed, but partial expansion was maintained and their auricles were reconstructed with a cartilage platform without a high conchal wall. In case 4 the auricle was rather flat, it has thin skin and contour was well-defined. It was evaluated as good. In case 5 the remaining cartilage was banked in the chest pocket and well-erected auricle was obtained with the elevation procedure with this banked cartilage and full thickness skin grafing. This auricle was evaluated as excellent. The patient data are summarized in Table 2.

From these observations the method presented here was evaluated as an overall good method and its application should be further extended.

\section{Discussion}

\section{Conventional methodology and associated problems}

Reconstruction of the auricle for microtia has been challenging problem for plastic surgeons. Converse ${ }^{3}$ and Tanzer ${ }^{4}$ reported the use of autologous rib cartilage framework in 1958 and 1959. Since then their methods especially Tanzer's method has been widely used with numerous modifications. As far as the material for the framework is concerned, the autologous rib cartilage has been the choice for almost all surgens. Some surgeons have advocated the use of other material such as a silicone platform ${ }^{9}$, but with the problems such as infection 

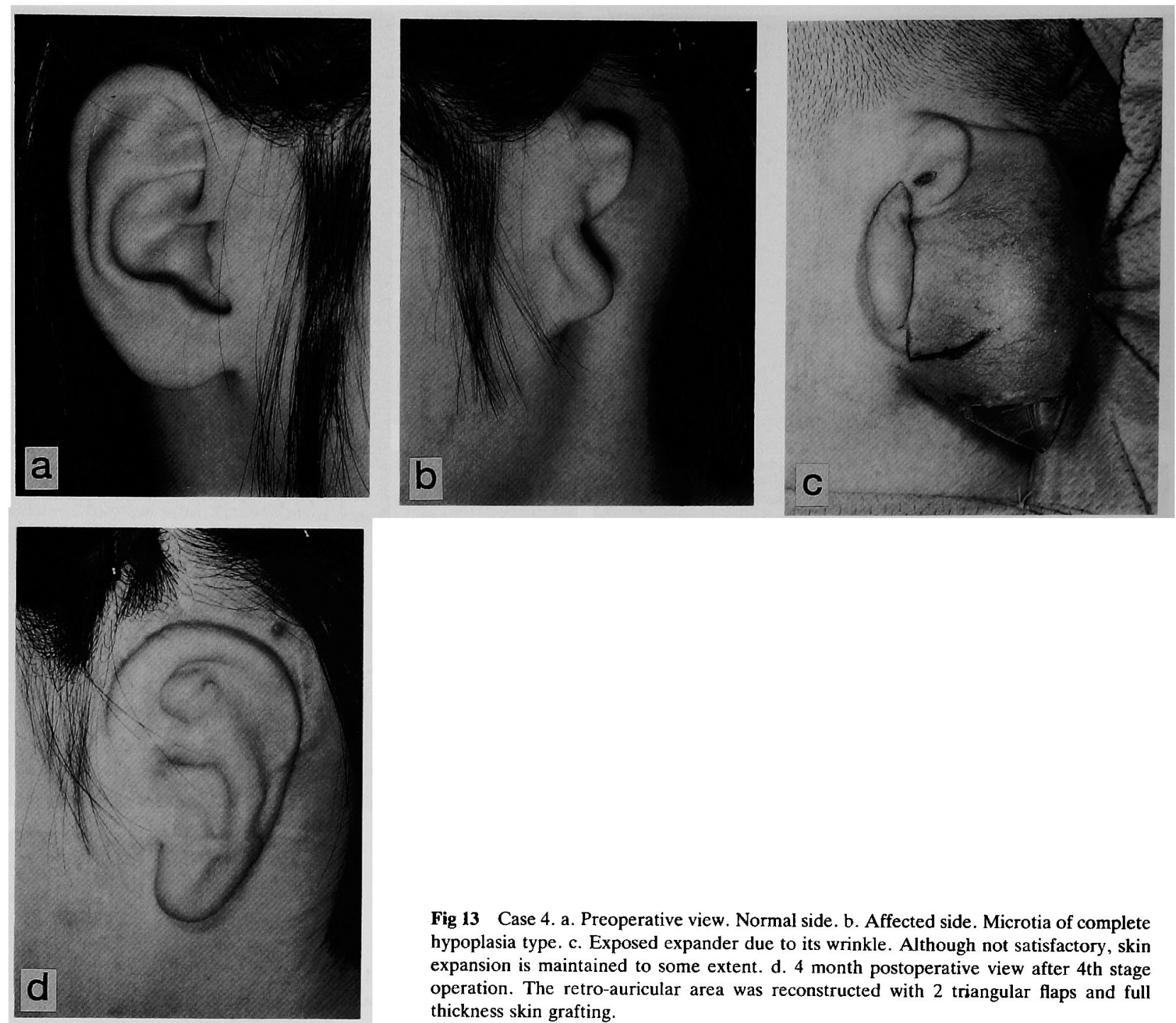

Fig 13 Case 4. a. Preoperative view. Normal side. b. Affected side. Microtia of complete hypoplasia type. c. Exposed expander due to its wrinkle. Although not satisfactory, skin expansion is maintained to some extent. d. 4 month postoperative view after 4th stage operation. The retro-auricular area was reconstructed with 2 triangular flaps and full thickness skin grafting.

and lack of long-term reliability, this method has not been widely accepted. In the Department of Plastic Surgery at Keio University, Tanzer's original method and its further modification has been indicated and satisfactory results have been obtained. Figure (15) shows the above-average result from the conventional method. Her auricle is well reconstructed in its general shape. However a close-up view reveals some problems. This ear (Fig. 15d) looks flat and lacks vivid, 3-D configuration.

The causes of the problems of the conventional method can be summarized into 2 factors. One is the shortage of the skin which to drape the platform and the other is the lack of three-dimensional model to be used as a template or an aid.

The shortage of the skin alone or with low-set hair line can be the cause of many problems: the malpositioning of the platform (low set ear, migration of the reconstructed ear into the face), hairy auricle (upper part) and loss of contour. In most of the microtia cases the temporal skin is not enough even for draping anterior surface of a modestly convoluted cartilage platform. The retroauricular side has to be skin grafted.

Hairy ear is also an annoying problem to both surgeons and patients. Because of the lack of the temporal skin, the upper part of the helix is likely to include hairbearing skin. In some cases electrical or surgical depilation is indicated. In an attempt to avoid this problem the entire reconstructed ear are sometimes located too low and become more difficult problem to solve. Another problem is the need for elevating the auricle, which consists of separating the cartilage platform from temporal skin and full thickness skin grafting. 

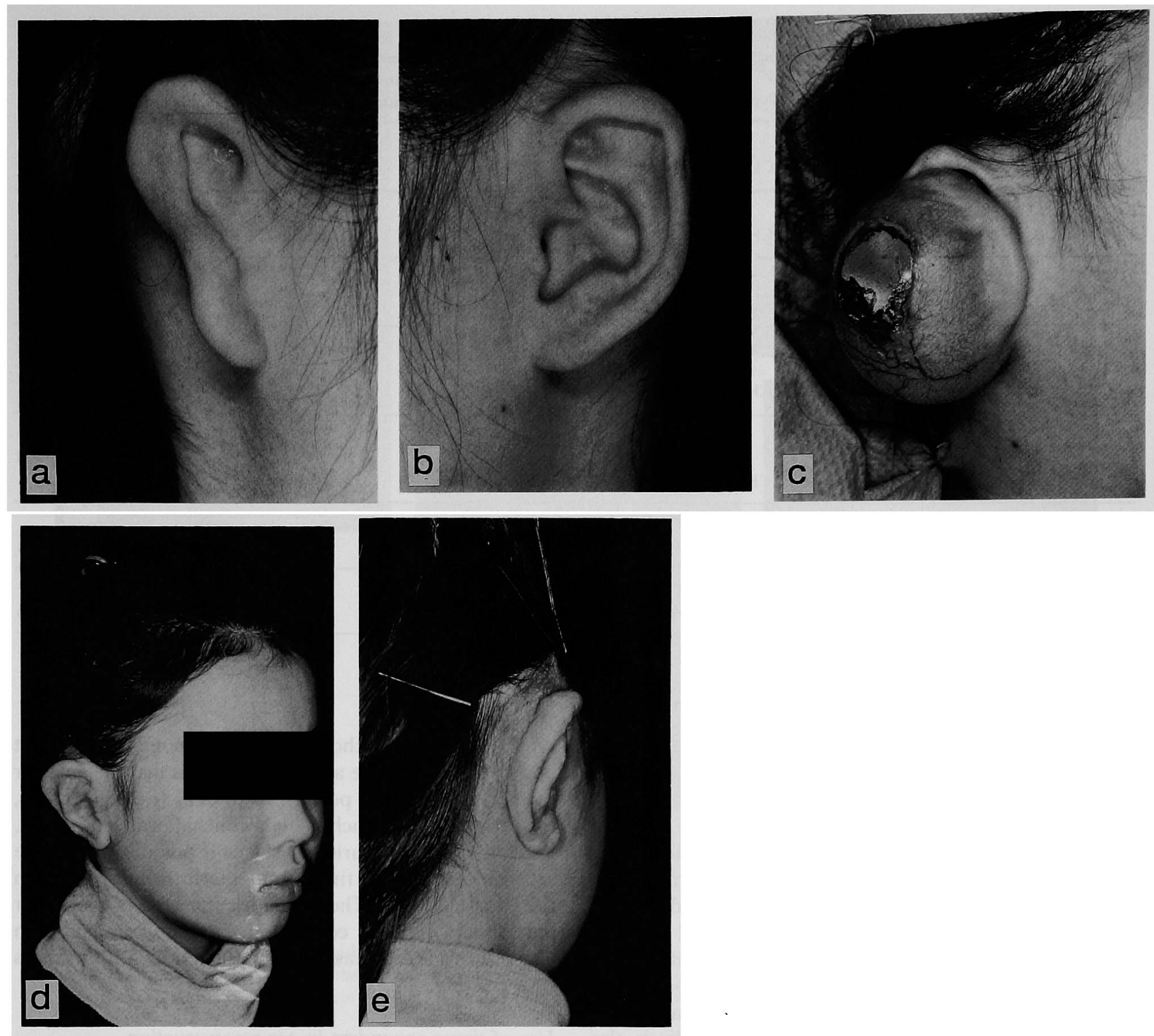

Fig 14 Case. 5. a. Preoperative view of the affected side. Microtia of complete hypoplasia type. b. Normal side. c. Exposed cxpander. This occurred during waiting period for the second stage after over expansion. The expander was maintained in place and skin expansion was kept continued although not satisfactory. d.,e. Final view. As the fourth stage ear elevation procedure with banked costal cartilage and full thickness skin grafting was performed. Note the well erect auricle with deep posterior sulcus.

The reverse film pattern has been widely used as a template or an aid. This can be taken from contralateral ear in unilateral microtia cases and the parents' ear in bilateral cases. Though this method is very simple and doesn't need any special instrumentation, it not only lacks 3-D information but also has inherent distorsion resulted from copying the shape of the 3-D auricle into 2-dimensional film. A Polaroid picture of the normal side (in some cases parents' ear) or exposing the normal side in the operative field may help the surgeon to make the platform more 3-D but still the surgeon himself has to make the 3-D mirror image in his mind. It has always been difficult to cover and reconstruct all the belowmentioned internal factors presicely.

Although the normal ear in young people has a thin and sligthly pinkish skin, following conventional methods the reconstructed ear tends to have thick and rather yellowish skin. This can be improved by making the temporal skin flap very thin. However this increases the risk of skin slough and resulting infection and absorption 
Table 2 Summary of Patients

\begin{tabular}{|c|c|c|c|c|c|c|c|c|c|c|}
\hline Case & Name & Age & Sex & Side & Type & Expander & $\begin{array}{c}\text { Total } \\
\text { volume }\end{array}$ & $\begin{array}{l}\text { Total no. of } \\
\text { Operations }\end{array}$ & Result & Complications \\
\hline 1 & & $9 y 2 m$ & $\mathrm{~F}$ & Lt & $\mathrm{CH}$ & $\begin{array}{l}\text { Koken \# } 1504 \\
\quad(55 \mathrm{ml})\end{array}$ & $73.5 \mathrm{ml}$ & 3 & Excellent & None \\
\hline 2 & & $7 \mathrm{y} 7 \mathrm{~m}$ & M & $\mathrm{Lt}$ & $\mathrm{CH}$ & $\begin{array}{l}\text { PMT \#3065-06 } \\
\quad(75 \mathrm{ml})\end{array}$ & $61.5 \mathrm{ml}$ & 4 & Good & $\begin{array}{l}\text { Unsatisfactory expansion } \\
\text { Ear elevation with FTSG }\end{array}$ \\
\hline 3 & & $10 \mathrm{y} 2 \mathrm{~m}$ & M & $\mathrm{Lt}$ & $\mathrm{CH}$ & $\begin{array}{l}\text { Koken \#1504 } \\
(55 \mathrm{ml})\end{array}$ & $84 \mathrm{ml}$ & 3 & Excellent & $\begin{array}{l}\text { Partial skin necrosis healed } \\
\text { by conservative therapy }\end{array}$ \\
\hline 4 & & $9 y 11 \mathrm{~m}$ & M & $\mathrm{Lt}$ & $\mathrm{CH}$ & $\begin{array}{l}\text { Koken \#1483 } \\
\quad(75 \mathrm{ml})\end{array}$ & $58.5 \mathrm{ml}$ & 4 & Fair & $\begin{array}{l}\text { Flat platform due to the } \\
\text { exposure of expander } \\
\text { Ear elevation with FTSG }\end{array}$ \\
\hline 5 & & $9 y 4 m$ & $\mathbf{F}$ & Rt & $\mathrm{CH}$ & $\begin{array}{l}\text { Koken \#1504 } \\
\quad(55 \mathrm{ml})\end{array}$ & $73 \mathrm{ml}$ & 4 & Excellent & $\begin{array}{l}\text { Exposure of expander } \\
\text { Ear elevation with banked } \\
\text { cartilage and FTSG }\end{array}$ \\
\hline 6 & & $8 y 5 m$ & $\mathrm{~F}$ & RI & CR & $\begin{array}{l}\text { PMT \#3610-18 } \\
\quad(95 \mathrm{ml})\end{array}$ & $89 \mathrm{ml}$ & 2 & Excellent & Reconstruction in progress \\
\hline 7 & & $9 y 3 m$ & $\mathrm{M}$ & $\mathrm{Lt}$ & $\mathrm{CH}$ & $\begin{array}{l}\text { PMT \#3610-18 } \\
\quad(95 \mathrm{ml})\end{array}$ & $84 \mathrm{ml}$ & 2 & Excellent & Reconstruction in progress \\
\hline
\end{tabular}

$\mathrm{CH}$ : Completc hypoplasia type

CR: Conchal remnant type

FTSG: Full thickness skin grafting

and deformity of cartilage platform.

\section{Reconstruction of the 3-D external ear}

There are a lot of points requiring attention when reconstruction of a natural and real 3-D external ear is planned. They can be devided into external and internal factors. The external factors are the position, size and inclination of the axis of the auricle. The internal factors are the shape of the individual auricle. A smooth helix and high conchal wall are very important because they are easily seen aspects of the ear. The antihelix is also important because it lies on top of the conchal wall. The tragus should be reconstructed because it casts shadow on the anterior edge of the conchal cup resembling the external meatus. In order to improve above mentioned problems, it is clear that the surgeon requires both the 3-D cartilage framework and a plentiful supply of a thin and pliable temporal skin through which every detail of the framework can be shown.

The life-sized mirror image model was useful in constructing the 3-D cartilage framework by giving precise details of the auricle and by relieving the surgeon from having to construct the 3-D mirror image from the Poraloid print in his mind. The model was enabled with the use of 3-D shape measurement system and this is the first published clinical application.

The expander was able to provide satisfactory amount of temporal skin although still not enough. The most important point in the author's opinion is that the anterior surface and the mid portion of the ear (i.e. the tragus, retrotragual pit, concha, high conchal wall and helix, antihelix and retroauricular sulcus if possible) shoud be reconstructed at the time of the platform insertion with the expanded skin. The retroauricular area of the upper part should only be covered if there is abundant skin because this area is easily reconstructed by full thickness skin grafting.

\section{Use of tissue expanders in ear reconstruction}

The first published report of the use of tissue expanders for ear reconstruction goes back to Neumann ${ }^{10}$ in 1957. And then Oneal $e t a^{11}$ in 1984 and Quaba ${ }^{12}$ in 1988 reported a case report. They all were indicated for the reconstruction of posttraumatic partial auricular defect.

Mutimer and Mulliken ${ }^{13}$ reported a case report of the correction of cryptotia using tissue expander.

Tanino et al..$^{5}$ began to use tissue expanders for microtia ear reconstruction from 1983 and their results were published in 1988. Their operative procedure consists of at least 4 stages. In the first stage the Radovan type expander is inserted into the temporal subcutaneous pocket. The autologous cartilage framework is usually made of the 6th, 7th and 8th costal cartilage and is roughly assembled at this time and buried in a sub- 

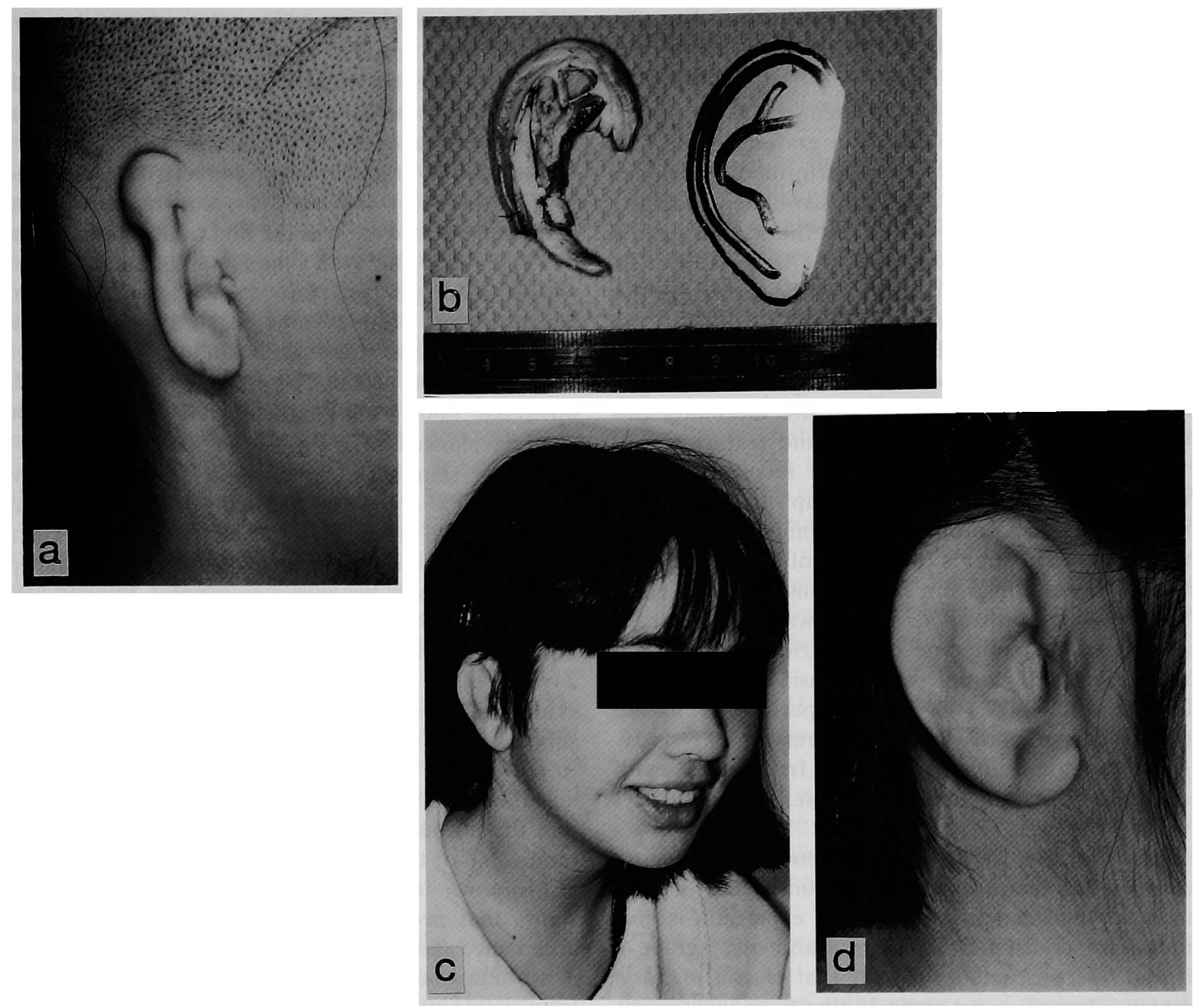

Fig 15 Auricular reconstruction with conventional methodology. a. Preoperative view. Microtia of complete hypoplasia type. b. Autologous cartilage platform and the reverse film pattern used as an aid. c. 2-year postoperative view after elevation and reconstruction of conchal cup with full thickness skin grafting. Natural looking auricle is obtained. d. Close-up view shows flat auricle lacking clear convolution.

cutanous pocket adjacent to the donor incision in the chest. Inflation of the expander is begun 2 to 3 weeks after its placement and is carried out once a week with increments of $5-10 \mathrm{ml}$ normal saline to the maximal expansion in 2 months. At the second stage ( 3 months after placement of the expander) the expander is removed and the capsule around it is excised. The prefabricated framework is retrieved from the chest pocket and final detailed carving is carried out and then embedded in the temporal pocket. At the third stage the auricle is detached from the temporal skin utilizing a full-thickness skin grafting from the inguinal lesion. Then the rotation of the lobulus is done at the fourth stage. If the depilation is needed it is done at the fifth stage. He evaluated that in his 35 cases 26 cases ( $74 \%$ ) exhibited excellent to good result, and 8 patients ( $23 \%$ ) had only a fair result (loss of contour) and one patient (3\%) had lost his expander owing to skin necrosis followed by infection. Complications are: exposure of expander in five patients $(14 \%)$, exposure of cartilage framework in four patients $(11 \%)$ and loss of contour in eight cases (23\%).

Tanino's problems are believed to lie not only in high complication rate but also in the inadequate use of expanded skin. The author agrees with Tanino that his main purpose of utilizing an expander for auricular reconstruction is bringing out contour details. However recruiting hairly skin into the helical rim and scapha and the elevation of the reconstructed auricle with full thickness skin grafting should be avoided as far as possible. The author believes this could be fascilliated 
with the use of a more 3-D framework which has distinctive, high conchal wall and economical use of the expanded skin.

Hata et $^{\text {al. }}{ }^{7}$ in 1988 reported their efforts to reconstruct an erect auricle without skin grafting using skin expanders. Their operation was performed in 3 main stages. At the first stage the lobule is switched back and the remnant cartilage is removed. At the second stage a rotated semielipsoid tissue expander $(70 \mathrm{ml})$ is inserted and then inflated to full expansion. At the third stage the ear framework is made from 6th, 7th, and 8 th rib cartilage as needed in their original fashion and inserted into the temporal subcutaneous pocket. Although the advantages of expansion such as minor donor site morbidity (no need for skin grafting), good color and texture match and near normal sensation are well recongnized, insufficient erection of the Hata group's reconstructed auricle seems to be a problem. The complication rate is rather high and 3 patients $(43 \%)$ out of a total of 7 had compications resulting from skin expansion, and 4 cases $(57 \%)$ in whom protruded auricle was reconstructed were conchal remnant type or constricted type. Only in one patient with complete hypoplasia could an erect auricle be obtained. This may be partly due to the particular design of cartilage platform in that study. A more anatomically-shaped 3-D frame-work with conchal support could contribute better to a naturallyprotruding ear.

Bauer ${ }^{14}$ reviewed reported experience of ear reconstruction using tissue expander, including the data of Hata et $a l .{ }^{7}$ and concluded that skin expansion is best indicated for conchal type microtia and cases grade 2 and grade 3 constricted ear, but that classic microtia (complete atresia) is not indicated because those cases can be reconstructed better without tissue expansion than with it. He also noted that the use of tissue expansion only to avoid skin grafting to the retroauricular sulcus alone is not sufficient reason for its indication. This indication of tissue expansion is perhaps contradictory, in that mild cases need skin expansion and severe cases do no need it. However it is accepted that avoidance of a skin graft to the retroauricular sulcus alone is not sufficient explanation to use skin expansion. It is clear that in classic microtia the temporal skin area is so small and the well-vascularized pliable skin is needed to reconstruct the complicated convolusions of the anterior surface of the auricle especialy from the tragus to the deep portion of the concha and the high and distinctive conchal wall. So expanded skin should be used mainly for anterior surface of the auricle not for the reconstruction of the retroauricular sulcus.

\section{Skin expansion and its advantages}

Skin expansion is a relatively new technique of pro- viding donor tissue, resulting an increase in the surface area of the expanded skin. Although soft-tissue expansion such as the expansion of the skin over the slowgrowing tumor or the abdomen of the pregnant women is a natural process, its introduction into plastic and reconstructine procudures is relatively new. Neumann's 1957 report $^{10}$ for the reconstruction of post-traumatic partial amputated ear was the first trial. The modern era was opened by Radovan's implantable, inflatable device with a semirigid backplate and a self-sealing remote injection port. From 1976 he began to present his work with this appliance for various kinds of problems ${ }^{15}$.

In 1980's the advantage of skin expansion was demonstrated both experimentally and clinically. Cherry et al. ${ }^{16}$. showed in a porcine model experiment that expanded skin has a significantly augmented survival length (117\% compared with controlled flaps). Austad et al. ${ }^{17}$ showed in the guinea pig model, that the expanded skin epidermis is not thinned but the dermis and panniculus carnosus become significantly thinner. Pasyk et al. ${ }^{18}$ in 1988 showed that the thickest capsule was observed between 2 and 2.5 months of expansion and at 2 years after completion of expansion the expanded skin underwent normalization, with the dermis and subcutaneous tissue demonstrating a thickness similar to that before expansion. The capsule was completely absorbed in 2 years. It was demonstrated by Thompson ${ }^{19}$ that the fibrous sheath disappears within 2 weeks after removable of the silicone implant.

Moreover Ito's recent experimental work in rabitts ${ }^{20}$ shows that pressure has a negtive effect on cartilage acceptance and that skin expansion utilizing an expander is advantageous not only from the apperance but also from the point of the cartilage.

\section{Problems in the use of tissue expanders in micritia total ear reconstruction}

The selection of the expander and extent of expansion

The size of the expander was determined from the data of the previous reports of Tanino ${ }^{5,6}$ et al. and Hata $^{7}$ et al. and by direct measurement of the patients' ear and remnant. Adhesive tape was applied and surface distance from posterior edge of the beard to temporal hairline was measured in all the seven patients. The average surface distance was $64.1 \mathrm{~mm}$ on the affected side and $113.3 \mathrm{~mm}$ on the healthy side. A distance of $49.2 \mathrm{~mm}$ were supposed to be obtained with the over-expansion of the $55 \mathrm{ml}$ expander or full expansion of $95 \mathrm{ml}$ expander. However because of the degree of the shrinkage of the expanded skin, this seemed insufficient for total ear reconstruction of a fully erect ear. It was thus determined to use the expanded skin primarily for the reconstruction of the anterior surface and mid-portion of the auricle and not for retroauricular area of upper part. In 5 patients 
on whom the skin expansion was done without any compications it was possible to reconstruct erect, 3-D auricle. These patients had $61.5 \mathrm{ml}-84 \mathrm{ml}$ saline in their expanders. One patient who had a limited saline injection of $61.5 \mathrm{ml}$ needed full thickness skin grafting to the retroauricular area but 3-D ear was successfully obtained. Judging from the above data the tissue expander should be inflated to at least $75 \mathrm{ml}$ to cover a well-erect, 3-D ear. This figure does not differ a lot from the optimal volume recommended by Hata et $a l^{7}$. However in order to reconstruct the total undulation including concavity just posterior to the tragus and conchal wall and helix, a larger capacity expander should be used to provide abundant skin. Although the shape of the expander seems nothing to do with the final result, the soft, nonwrinkle and seemless type of expander is desirable.

PMT No. $3610-18(6 \mathrm{~cm}$ in length $\times 5 \mathrm{~cm}$ in width $)$ just fits nicely in the temporal non hair-bearing area and meets the above-mentioned requirements at this time.

Whether the expansion should be left in place for a while in order to prevent shrinkage is another unsolved problem. It is known that the expanded skin shrinks less when the expander is kept in place for a few months. However, this principle should perhaps not be applied in this region, because the skin is too thin to withstand every day minor trauma. In this series, Case 5. developed exposure in this wating period so at this time the second stage is scheduled immediately when a satisfactory skin surface area is obtained.

\section{The handling of the capsule}

The handling of the capsule arround the expander is still controversial. Tanino et al. ${ }^{5,6}$ remove all of the capsule except where the skin is too thin. Hata et al. ${ }^{7}$ generally did not remove the capsule and incised only one third of the circumference. In this series the author's team did not take the capsule out except for the anterior and upper portions because the skin is to thin and the small axial vessels run just above the capsule, so that removing the capsule may negatively affect the vascularity of the expanded skin. The anterior part of the capsule near the remnant and upper portion were removed because the capsule tissue might have obscured the contour of the anterior crus of the helix and tragus. Although other portions of the capsule were in general not removed, in most of the patients the base of the hard triangular capsule at the edge (periferal margin) was incised in deep layer with meticulous care not to damage the fine vessels on the capsule in order to obtain advancement of the skin in a central direction. Capsules are expected spontaneously to resolve rapidly from Thompson's observation ${ }^{19}$ and the author feels that they need not be removed, especially with the risk of skin necrosis.

\section{Retraction or shrinkage of the expanded skin}

It is known that the expanded skin retracts to some extent although the mechanism is not fully explained, and that the expanded skin tends to contract less on a rigid framework.

The extent of shrinkage seems to differ by location. Scalp skin is likely to retract more than the non hairbearing temporal skin so in this series the scalp was not expanded and not recruited for helix. The cases with the greater total expansion volume tended to have thinner, more pliable skin and obtained better anterior draping and posterior sulcus.

\section{Exposure of the expander}

Exposure of the expander is one of the worst complications of the tissue expander. Although case 4 and 5 developed this problem, excellent and fair result could be obtained. From the author's experience this complication can be well handled with meticulous care and does not affect a lot to the final result. In such a case avoidance of infection and banking of rib cartilage for later auricular elevation should be considered.

Utility of the 3-D shape measurement system for human figure measurement

\section{Advantage of noncontact 3-D measurement system}

The advantage of free surface (non-contact) measurement is that it doesn't create any distortion caused by pressure during measurement and it is safe, clean and easily repeated.

In order to obtain 3-D measurement, 3-D digitizer has been often used. In the medical field, some of these examples are the anthropometrical measurment of the human skull and documentation of the occulusion cast model of patients with the cleft palate ${ }^{21}$. However 3-D digitizer is not appropriate for large ares of in-vitro measurement in humans because the object must be on the digitizing table and the human body is made up of multiple smooth and complicated surfaces. In such a case, the measurement points tend to be too many, and the object need to be absolutely still for a long period of time.

On the other hand, despite the fact that it is inferior in accuracy to the digitizer, the free surface 3-D measurement system based on a laser slit-lamp scanner is very suitable for human measurement because it enables quick pattern measurement.

\section{Introduction of free-surface measurement technology to the medical field}

Moss and his group ${ }^{22-24}$ developed a speciallydesigned no-contact laser scanning system for studying changes in the facial form. Their system consisted of scanning head with two laser beams, rotating mirrors 
and a video camera employing DMA (Direct Memory Access) interface and Norsk computer. The patient is seated on a chair which is rotated by a stepper motor under computer control. The data for each profile is obtained in one twenty-fifth of a second. Geometrical transformations are then applied to convert the raw data into a set of approximately 300 spatial coordinates. The precision of this system is $0.5 \mathrm{~mm}$. The data of the entire face consisting of 24,000 measurements is recorded in approximately 30 seconds. Data is sampled at intervals of 1 degree over the nose and intervals of 3 degree over the rest of the face. The facial coordinates are stored in the computer disc and floppy discs. Moss and his colleagues also developed a three-dimensional visualization technique for skull and facial skeleton from CT scans and proposed the possibility of surgical simulation.

Cutting et al. ${ }^{25}$ in 1988 introduced the Echo Scanner manufactured by Cyberware Laboratories. The principle of this system is somewhat more simple compared to Moss's system. The scanning head has only one laser beam and the patient is seated on the computer-controlled rotating chair but has a higher resolusion of 500 scan lines in each video frame.

The data are transfered to a Silicone Graphics Iris 2400 graphics workstation and processed to produce three-dimensional images using the group's original software. A point-to-point three-dimensional measurement capability is provided.

Although at the time their paper was written there was no practical utilization in the literature, the authors proposed the possible usage of the system in maxillofacial surgery, breast surgery, rhinoplasty and body contouring surgery such as liposuction.

\section{The Voxelan system}

As the principle and hardware construction of the Voxelan system have been discussed and shown before, only the difference between the Voxelan system and the above-mentioned systems are discussed here.

The principle and hardware construction is similar to Moss's system in that both system have adopted the triangulation method with one VTR camera and 2 rotating mirrors. Although both Moss and Cutting use a compute-controlled rotating chair for full-face measurement, this tends to create many blind spots. From the experience of the author of the present study and his group, the optical head should be rotated feely to measure complicated human parts. In order to make full face measurement, compilation of the data from various angles is more appropriate, and the mobile arm and software are now being developed to accomplish this.

The principle of Cutting's system is different from the Voxelan system. As Cutting's system uses only one laser beam the resolusion tends to become low when the object being measured is at an angle because the slit lamp projected laser beam diverges, or becomes wider, on the object.

The use of both systems in a dark room is recommended in order to reduce interference from extraneous light sources becuase they do not have any light-masking process.

The accuracy depends on the degree of the projected angle of the laser beam, the width of the beam, the speed of the beam and system resolution. If the object is $10-30 \mathrm{~cm}$ and the angle of the laser beam is 45 , accuracy is determined by the system resolution. In other words, accuracy is determined by the number of pixels: when the pixel resolution is $256 \times 240$ and the measurement field $130 \mathrm{~mm} \times 122 \mathrm{~mm}$, the accuracy range is to within $0.4 \%,(0.5 \mathrm{~mm})$ and is thus almost negligible for auricular reconstruction. Although the accuracy goes up to $0.2 \%$ with the high resolution model of $512 \times 480$ pixels, this system is not recommended for human measurement because of long measurement time required, which is double the standard system. The accuracy and resolution of the milling machine is also very high $(0.01 \mathrm{~mm} / \mathrm{step})$, and is thus also negligible.

For measurement of human subjects the speed of measurement is a very important factor. The laser scanning time is 4 seconds for one beam and is carried out on both sides, so the measurement can be completed in just 10 seconds. From the author's experience this is short enough for measurement of the ear, face, hand and chest of the adult patient. However a chair with a headrest is needed to immobilize the head of the microtia patients.

The shape reconstruction time is about 30 seconds: the result can be checked on the TV monitor immediately and the measurement can be repeated. The measurement of the both the anterior and posterior surfaces of the both sides of ears took about 10 minutes. As this system employs a high resolution scanning system and real-time encoding of projection angle of slit lamp, it gives a high rate of reliablility and repeatability.

In the measurement system based on the triangulation method, as the angle between the scanned (laser) light and the axis of the lens system of the TV camera determines the accuracy, the shadow area i.e. blind spots increases as the object gains in surface complexity. This system can minimize blind spots by collecting data from 2 directions creating different shadows, and then extracting effective area by a process of image subtraction. However it was impossible to eliminate the blind spots just under the hooding of the helix and posterior surface of the tragus because it has the only one TV camera and therefore inevitably result in some blind spots. Fortunately these area are situated out of normal view, and are not expected to be reconstructed. Blind spots can be effectively eliminated by adjusting the optical head so that the axis of the lens system of the TV camera cuts the object at the same angle as through the TV 
monitor. For the anterior surface measurement of the ear with the hooded helix, a slight elevation of the angle was appropriate. In most of the measurement of the posterior surface, the head was rotated through 90 .

Although at this time the measurement and creation of the ear model are done for both anterior view and posterior view separately, i.e. 2 models for one ear, the creation of composite data from multiple angles will become possible in the near future by the development of special software.

\section{Comparizon of the methods for making ear model}

In this paper the usefulness of the mirror image lifesize wax model taken from the normal side is clealy demonstrated as an aid to reconstruction. Although the reverse film pattern is still useful in precise positioning of the cartilage framework, the framework itself should be assembled three-dimensionally with the aid of the mirror image model.

It is however not easy to make a simple cast model of the external ear as is expected, other than using this method. The ear is too soft to take an impression with the usual dental materials and there will always be some degree of distortion. Because of the extremely complicated auricular configeration, it is easy to break or damage the dental molding material when the cast model is being detatched from the mold.

Making mirror-image model can only become possible with the help of either artristic work or computer technology. The former is time consuming and expensive. It may be possible to make mirror-image ear model based on the data from computed tomography (CT) and magnetic resonance imaging (MRI). However CT has a problem of the resolusion $(0.5 \mathrm{~mm}$ in axial plane and at the most $2 \mathrm{~mm}$ in vertical plane) coupled with the radiation exposure, and is not practically indicated for the deformities of body surface soft tissue only. MRI for this purpose, while more accurate and better than CT for soft tissue work, is not cost-effective.

\section{Further applications for auricular reconstruction}

\section{Determination of the size of the tissue expander}

Hata et al. ${ }^{7}$ reported the mean surface area of ten normal adult Japanese ear as $52 \mathrm{~cm}^{2}$. However as each ear differs a lot in size and shape so does the surface area. Recently a new software (3-D Sphinx from Kashimura Co. Ltd.) has been developed to calculate distance, surface area and volume from the data obtained with the three-dimensional surface measurement system (Fig. 16). Although this software need more refinement and calibration, it is expected to provide practical and useful data in determing the size of expanders.

\section{Application in reconstruction of bilateral microtia}

In bilateral microtia patients, it would be wise to measure the parents' ear and make the life-sized model from this data and reproduce the cartilage framework to simulate that ear model. Characteristics of the parents' ear can be combined, such as the size from the father, and the shape from the mother. This concept of customized ear designed should be welcomed as most families have few children.

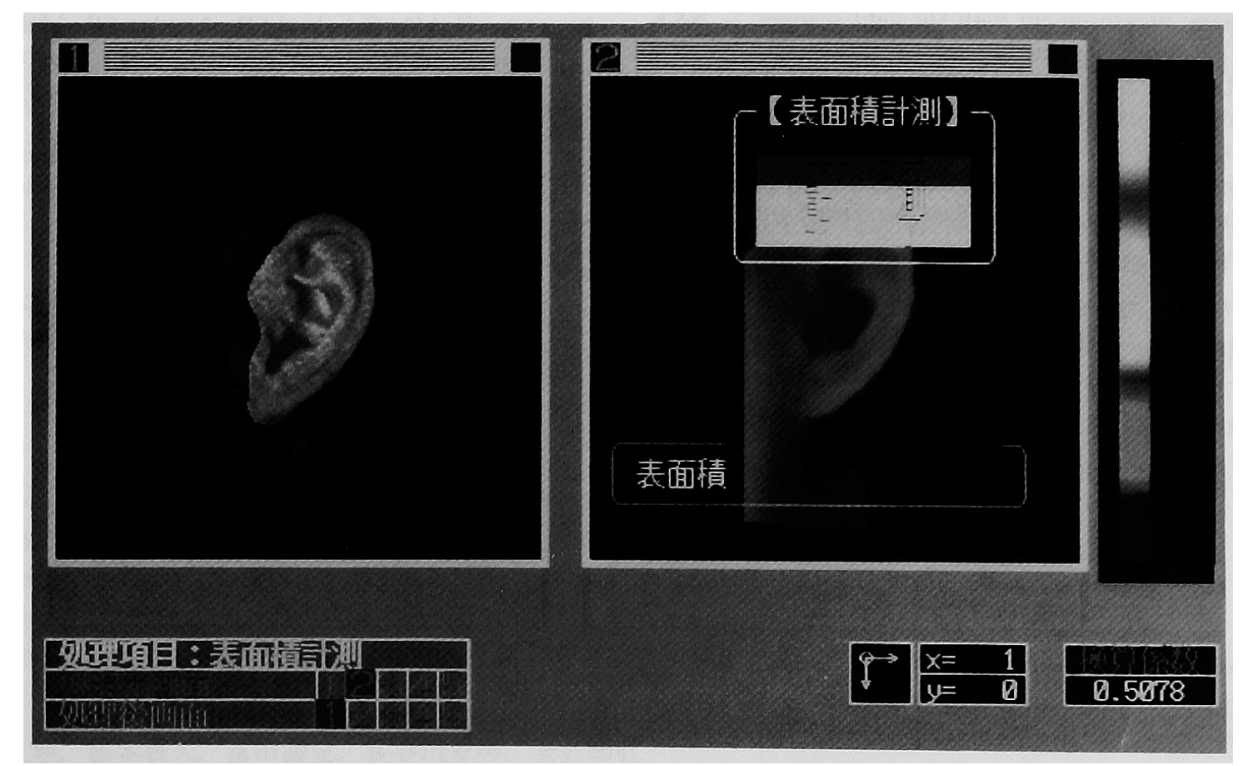

Fig 16 Screen display of 3-D Sphinx (from Kashimura Co. Ltd.) measuring surface area of the auricle. 


\section{Postoperative evaluation and documentation}

Although the documentation of the postoperative result can be achieved by anthropometrical measurement and photography, 3-D digital data and life-sized model have a distinct value for evaluation and documentation.

Acknowledgement: The author is deeply indebted to Toyomi Fujino MD, Professor and Chairman of the Department of Plastic Surgery, School of Medicine, Keio University for his support in this investigation. He is also grateful for a direction of Hideo Nakajima MD, Associate Professor in Plastic Surgery. He would like to thank Moriguchi M, Itoh $\mathrm{M}$, Inomata $\mathrm{M}$ and Uesugi M (NKK Cooporation) for their technical assistance. He would also thank Glen Calderhead for editing the manuscript. A part of this study is supported by the Grant in Aid for Scientific Research (A) 04857128 from the Jpn Ministry of Education, Science and Culture.

\section{References}

1. Grabb WC: The first and second branchial arch syndrome. Plast Reconstr Surg 1966, 36: 485-508

2. Conway $\mathrm{H}$, Wanger $\mathrm{KJ}$ : Congenital anomalies of the head \& neck. Plast Reconstr Surg 1965, 36: 71-79.

3. Converse JM: Reconstraction of the auricle. Plast Reconstr Surg 1958, 22: $150-167$

4. Tanzer RC: Total reconstruction of the external ear. Plast Reconstr Surg 1959, 23: 1-15

5. Tanino R. Nishimura N, Miyasaka M, Yamaguchi H, Morita, T. Yamada $H$. Osada $M$ : Reconstruction of microtia using tissue expander. Jpn J Plast Reconstr Surg 1988, 31: 585-593 (in Japanese)

6. Tanino R, Miyasaka M: Reconstruction of microtia using tissue expander. Clin Plast Surg, 1990, 17: 339-353

7. Hata Y, Hosokawa K, Yano K, Matsuka K, Ito O: Correction of congenital microtia using the tissue expander. Plast Reconstr Surg 1989, 84: 741-753

8. Uesugi I. Inomata. M: 3-D shape measurement with image encoder - Shape measurement with slit light scanner - NKK Gihou 1989, 129: 71 -78 (in Japanese)

9. Cronin TD: Use of a silicone frame for total and sub-total reconstruction of the external ear. Plast Reconstr Surg, 1966 37: $399-405$

10. Neumann CG: The expansion of an area of skin by progressive distension of subcutaneous balloon. Plast Reconstr Surg 1957, 19:
124- 130

11. Oneal R, Rohrich RJ, Izenberg PH: Skin Expansion as an adjunct to reconstruction of the external ear. Br J Plast Surg 1984, 37: 517-519

12. Quaba, A: Reconstruction of a post traumatic ear defect using tissue expansion: 30 years after Neumann. Plast Reconstr Surg 1988, 82: 521-524

13. Mutimer KL, Mulliken JB: Correction of cryptotia using tissue expansion. Plast Reconstr Surg 1988, 81: 601-604

14. Bauer BS: The role of tissue expansion in reconstruction of the ear. Clin Plast Surg 1990, 17: 319-325

15. Radovan $C$. Tissue expansion in soft-tissue reconstruction. Plast Reconstr Surg 1984, 74: 482-492

16. Cherry GW, Austad E, Pasyk KA, McClathey K, Rohrich RJ: Increased survival and vascularity of random pattern flaps elevated in controlled, expanded skin. Plast Reconstr Surg 1983, 72: $680-687$

17. Austad ED, Pasyk KA, McClathey KD, Cherry GW: Histomorphologic evaluation of guinea pig skin and soft tissue after controlled tissue expansion. Plast Reconstr Surg 1982, 70: 704-710

18. Pasyk KA, Argenta LC, Hassett C: Quantitative analysis of the thickness of human skin and subcutaneous tissue following controlled expansion with a silicone implant. Plast Reconstr Surg 1988, 81: 516-523

19. Thompson HG: The fate of the pseudosheath pocket around silicone implants. Plast Reconstr Surg 1973, 51: 667-671

20. Ito $O$ : Experimental study on the behavior of costal cartilage transplanted under expanded skin. Jpn J Plast Reconstr Surg 1991, 11: 916-926 (in Japanese)

21. Galic M, Marsh JL, Huebener D, Bresina S, Vannier MW, Bartel T: 3-D evaluation of the maxiallary alveoar arch from birth through 14 months of age in complate unilateral cleft lip/palate. abstract from Am. Cleft Palate-Craniofacial Assoc. Meeting 1990

22. Arridge SR, Moss JP, Linney AD, James D: Three-dimensional digitization of the face and skull. J Oral Maxillofac Surg 1985, 13: $136-143$

23. Moss JP, Linney AD, Grindrod SR, Arridge SR, Clifton JS: Three-dimensional visualization of the face and skull using computerized tomography and laser scanning techniques. Eur J Orthod 1987, 9: 247-253

24. Linney AD, Grindrod SR, Arridge SR, Moss JP: Three-dimensional visualization of computerized tomography and laser scan data for simulation of maxillo-facial surgery. Med Inf 1989, 14: $109-121$

25. Cutting CB, McCarthy JG, Karron DB: Three-dimensional input of body surface data using a laser light scanner. Ann Plast Surg $1988,21: 38-45$ 